\title{
PENERAPAN HUKUM BERNOULLI PADA KONSEP PERANCANGAN GALERI PESAWAT TERBANG DAN KANTOR SEWA DI KEMAYORAN
}

\author{
Willy Steven Febrianto ${ }^{1}$, Fermanto Lianto $2 *$ \\ ${ }^{1}$ Program Studi Sarjana Arsitektur, Fakultas Teknik, Universitas Tarumanagara Jakarta \\ Email: willyst.architect@yahoo.com \\ ${ }^{2 *}$ Program Studi Sarjana Arsitektur, Fakultas Teknik, Universitas Tarumanagara Jakarta \\ Email: fermantol@ft.untar.ac.id \\ *: Corresponding Author
}

\begin{abstract}
ABSTRAK
Seiring perkembangan zaman, daerah Kemayoran berubah fungsi menjadi daerah perkantoran, sehingga sejarah Kemayoran semakin lama semakin tergerus. Namun, kita tidak dapat menolak arus perkembangan zaman, terlebih daerah Kemayoran yang memiliki potensi menjadi daerah Central Business District (CBD). Setelah melakukan pencarian data dengan melakukan wawancara dan survei di kawasan Kemayoran serta mengkaji literatur, maka digunakan teori urban acupuncture untuk menjawab fenomena yang terjadi, yaitu sebuah galeri sejarah pesawat terbang dan fungsi tambahan kantor sewa akan dijadikan sebuah tempat wisata edukasi dimana orang-orang dapat melihat berbagai koleksi pesawat dari zaman penjajahan Belanda, Jepang, dan saat Indonesia merdeka, serta untuk memenuhi fungsi Kemayoran sebagai daerah CBD. Bangunan ini memiliki konsep perancangan yang diambil dari hukum Bernoulli yakni pergerakan udara saat melewati sayap pesawat dan memiliki tema kedirgantaraan. Galeri dan kantor sewa ini akan didukung dengan progam seperti ruang pertunjukan film, perpustakaan, ruang eksibisi pesawat dengan skala 1:1, dan workshop. Dengan adanya bangunan ini, diharapkan sejarah Kemayoran dapat dikenal luas oleh semua kalangan dan menjadi sarana edukasi khususnya bagi generasi muda.
\end{abstract}

Kata kunci: Bernoulli; Galeri; Kantor Sewa; Pesawat Terbang; Urban Acupuncture

\begin{abstract}
Along with the times, the Kemayoran area changed its function to become an office area, so that the history of Kemayoran is increasingly eroded. However, we cannot refuse the current of the times, especially the Kemayoran area, which has the potential to become a Central Business District (CBD). After searching the data by conducting interviews and surveys in the Kemayoran area and reviewing the literature, the urban acupuncture theory is used to answer the phenomenon that occurs, namely an aircraft history gallery and the additional function of the rental office will be used as an educational tourist spot where people can see various collections of aircraft from the Dutch, Japanese and Indonesian colonial times, and to fulfill Kemayoran's function as a CBD area. This building has a design concept taken from Bernoulli's law which is the movement of air as it passes through the wings of an aircraft and has a theme of aerospace. This gallery and rental office will be supported by programs such as movie showrooms, libraries, airplane exhibition rooms with a scale of 1:1, and workshops. With this building, it is hoped that the history of Kemayoran can be widely known by all circles and become a means of education, especially for the younger generation.
\end{abstract}

Keywords: Airplane; Bernoulli; Gallery; Rental Office; Urban Acupuncture

\section{PENDAHULUAN}

Jakarta sebagai ibu kota Indonesia, banyak sekali menyimpan sejarah mulai dari penjajahan Belanda hingga Jepang. Salah satu daerah di Jakarta yang mulai terlupakan sejarahnya adalah Kemayoran, Jakarta Pusat. Kemayoran memiliki sejarah yang penting bagi perkembangan transportasi udara bangsa Indonesia, dan Bandara (Bandar Udara) Kemayoran merupakan kebutuhan vital pada saat itu.

Seiring perkembangan zaman, daerah Kemayoran lama-kelamaan berubah fungsi menjadi daerah perkantoran. Sejarah Kemayoran semakin terlupakan dan tergerus zaman, terlebih untuk generasi 
muda. Namun, di satu sisi kita juga tidak bisa melupakan perkembangan zaman. Disamping itu daerah Kemayoran yang memiliki potensi sebagai daerah Central Business District, sehingga diperlukan adanya suatu tempat yang dapat mengingatkan kita kembali akan sejarah awal Kemayoran sebagai bandara internasional pertama di Indonesia dan tempat yang menunjang aktivitas bisnis untuk daerah Kemayoran. Selain itu menara Air Traffic Control (ATC) Kemayoran menjadi menara pertama yang ada di Asia dan di tetapkan sebagai cagar budaya oleh pemerintah Indonesia, sesuai dengan Keputusan Gubernur DKI Jakarta No.495 Tahun 1993, tentang Penetapan bangunan-bangunan bersejarah di daerah khusus Ibukota Jakarta sebagai benda cagar budaya (Soedirja, 1993).

Dengan mengacu pada teori urban acupuncture diharapkan sejarah penting kawasan Kemayoran dapat dikenal luas oleh seluruh kalangan baik dalam Jakarta maupun luar Jakarta, menjadi sarana edukasi khususnya pelajar, sebagai destinasi wisata warga Jakarta, dan menjadi identitas Kemayoran serta tidak melupakan perkembangan zaman khususnya di daerah Kemayoran. Sehingga sejarah tersebut tetap di kenang, seperti ucapan Soekarno kepada bangsa Indonesia yakni: "Jasmerah", jangan sekali-kali melupakan sejarah (Kurniawan, 2011).

\section{METODE PENELITIAN}

Metode yang digunakan adalah metode kualitatif melalui studi literatur sebagai pedoman dalam menentukan standar luas sebuah ruangan seperti: Neufert Architects' Data (Neufert, 2012:333-335, 352-358, 446-448), Time-Saver Standard (De Chiarra \& Callender, 1987:935-940), serta melakukan pengamatan data dengan melakukan wawancara dan survei di kawasan Kemayoran, serta menerapkan teori urban acupuncture di kawasan kemayoran untuk menyelesaikan fenomena yang terjadi dan penerapan hukum Bernoulli sebagai konsep perancangan yang merupakan prinsip dasar pembuatan pesawat terbang.

\section{KAJIAN TEORI}

Urban acupuncture pada dasarnya merupakan teori urban environment yang menggabungkan ilmu perkotaan kontemporer dengan ilmu pengobatan tradisional Cina. Urban acupuncture berproses menggunakan intervensi skala kecil untuk mengubah konteks perkotaan yang lebih besar (Casagrande, 2014:16-18). Lokasi di pilih melalui analisissintesis dan berbagai faktor sosial, budaya, sejarah, ekonomi, ekologi, dan politik. "Obat yang baik" bergantung pada hubungan antara pasien dan dokternya, sama seperti sebuah kota, kota yang sehat bergantung pada kerja sama antara perencana kota, desainer, dan kota itu sendiri sebagai sebuah organisme. Perencanaan kota yang baik dapat membangkitkan peluang-peluang, dan menciptakan kehidupan baru. Akupuntur yang berakar dari pengobatan Cina, urban acupuncture membutuhkan waktu untuk menciptakan suatu kesembuhan bagi kota. (Lerner, 2016:123-125)

Galeri adalah ruangan atau gedung tempat memamerkan benda atau karya seni dan sebagainya (KBBI, 2018: https://kbbi.web.id/galeri); "Gallery: a room or building that is used for showing works of art, sometimes so that they can be sold" (Dictionary, 2018: https://dictionary.cambridge.org/dictionary/english/gallery); "A room or building for the display or sale of works of art" (Dictionaries, 2018:717). Galeri adalah tempat menjual benda seni, berbeda dengan museum yang tidak boleh melakukan transaksi, kecuali koleksikoleksi cenderamata di toko souvenir. 
Kantor adalah unit organisasi yang terdiri atas tempat, karyawan, dan operasional ketatausahaan untuk membantu pimpinan (Atmosudirdjo, 1982:25); balai (gedung, rumah, ruang) tempat mengurus suatu pekerjaan atau juga disebut tempat bekerja (KBBI, 2018: https://kbbi.web.id/balai); "A room, set of rooms, or building used as a place for commercial, professional, or bureaucratic work” (Dictionaries, 2018:434).

The Bernoulli Effect: dengan adanya kecepatan aliran fluida yang meningkat, maka tekanannya akan turun. Efek Bernoulli ini memiliki banyak aplikasi dalam kehidupan nyata dan sering disebut sebagai sayap pesawat terbang yang memberikan daya angkat. Sayap dibentuk sedemikian rupa (lihat gambar 1) sehingga udara mengalir lebih cepat di sayap bagian atas dari pada bagian bawah, yang akan menghasilkan perbedaan tekanan dan menimbulkan daya angkat terhadap pesawat (Bernoulli, Mei 2016).

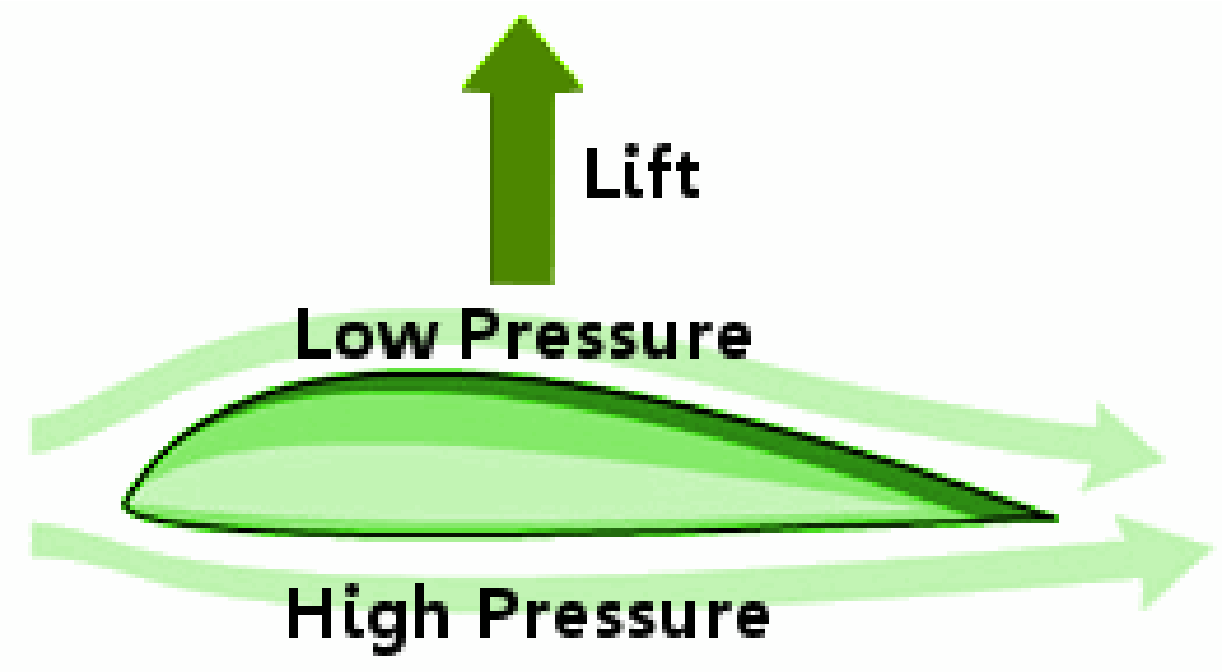

Gambar 1. The bernoulli effect pada sayap pesawat terbang.

Sumber: http://www.famousscientists.org/daniel-bernoulli/, diunduh 28 September 2018.

\section{HASIL DAN PEMBAHASAN}

Dengan teori urban acupuncture, ditambahkan bangunan galeri pesawat terbang untuk menjawab fenomena hilangnya sejarah penting kawasan Kemayoran dan tambahan fungsi kantor sewa sebagai Central Business District kawasan Kemayoran, menjadikan kawasan Kemayoran sebagai destinasi wisata dan bisnis.

\section{Konsep dan tema}

Konsep dan tema bangunan galeri diambil dari ciri khas fungsi bangunan galeri yaitu tema yang berhubungan dengan kedirgantaraan yang berisi segala macam pengetahuan tentang teknologi pesawat terbang yang pernah mendarat dan lepas landas di Bandara Kemayoran. Konsep perancangan memanfaatkan hukum Bernoulli yang biasa diterapkan pada teknologi pesawat terbang yaitu pergerakan udara saat melewati sayap pesawat (Lihat gambar 1). Dengan bentuk sayap pesawat yang khas dan mengikuti hukum Bernoulli, mengakibatkan udara akan membentuk pola tertentu dan menghasilkan high pressure dan low pressure pada posisi yang tepat sehingga akan mengangkat atau menurunkan pesawat. Pola bentuk sayap pesawat ini yang diambil sebagai konsep dasar bentuk bangunan khususnya pada tower bangunan galeri dan kantor sewa (lihat gambar 2b dan 8). Disamping itu juga diterapkan konsep solid dan void pada 
pengolahan denah (lihat gambar 7) dan tampak bangunan (lihat gambar 4 dan 8), hal ini dimaksudkan untuk lebih memperkuat penerapan hukum Bernoulli yang memberikan perbedaan tekanan udara akibat aliran udara yang menimpa bangunan, sekaligus berfungsi untuk menurunkan temperatur di dalam ruangan, karena udara panas akan terdorong ke atas bangunan melalui void yang terbentuk (lihat gambar 3) dan menghapus kemonotonan penampilan tampak bangunan dengan adanya pengolahan denah solid dan void tersebut (lihat gambar 8).


Gambar 2. Penggunaan sistem struktur space frame pada atap galeri dilihat dari arah dalam ruangan (interior) dan luar bangunan (eksterior).

Sumber: Penulis, 2019
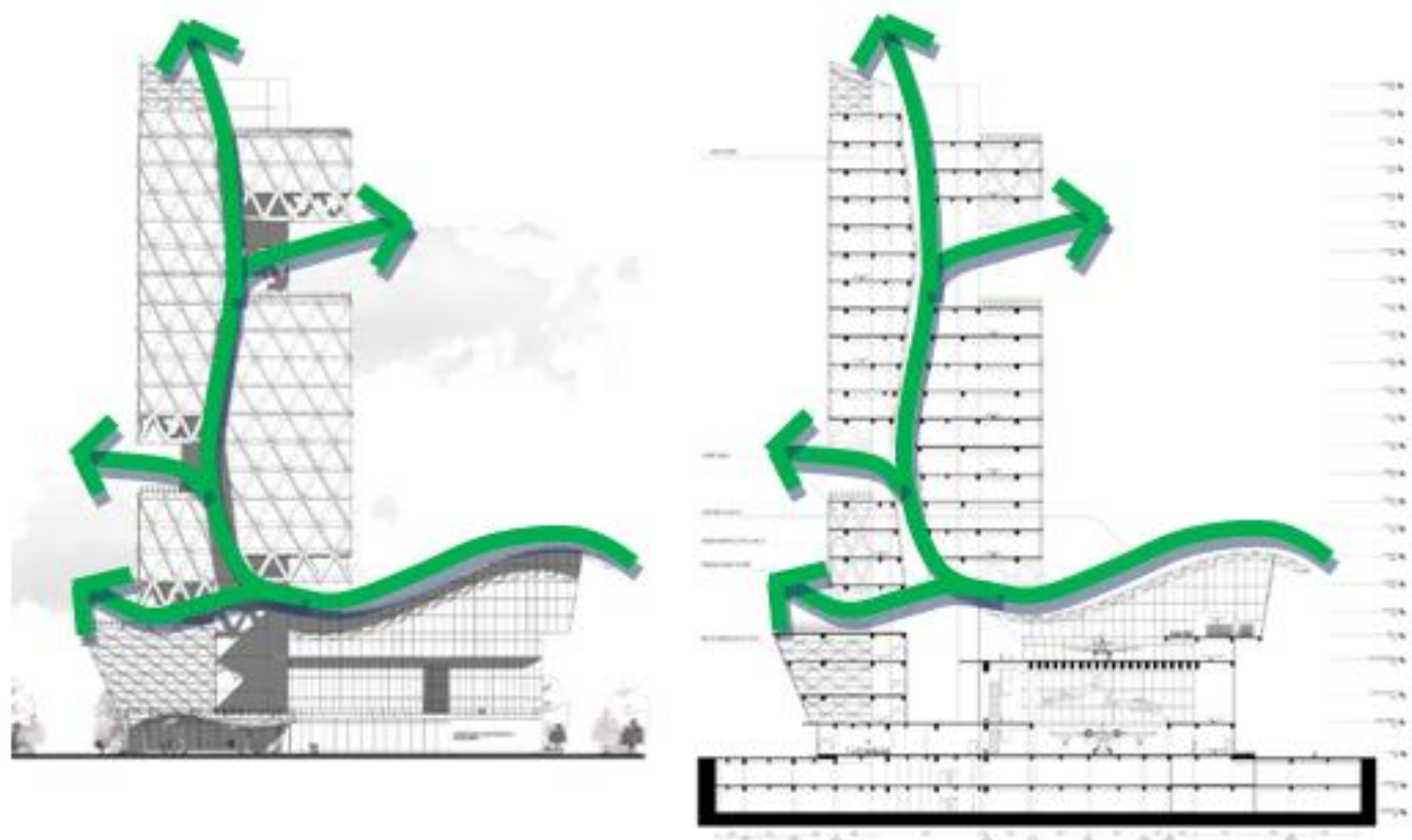

Gambar 3. Penerapan konsep hukum bernoulli pada pengolahan denah yang terlihat pada tampak bangunan.

Sumber: Penulis, 2019 

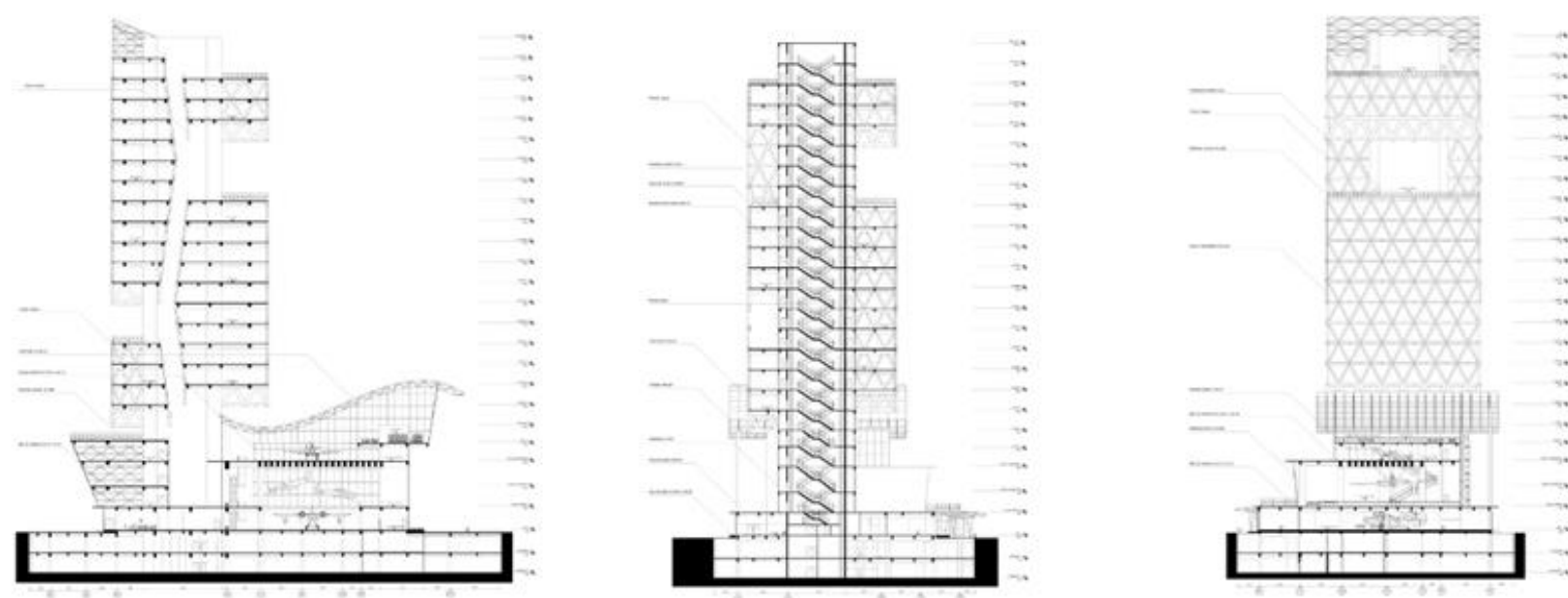

Gambar 4. Potongan A-A, B-B dan C-C.

Sumber: Penulis, 2019

\section{Konsep sistem struktur}

Pemakaian sistem struktur space frame sangat cocok sebagai konstruksi atap, dan merupakan suatu cara untuk mewujudkan "suasana bandara" dalam bangunan galeri karena dipergunakan untuk meletakan model pesawat terbang dengan skala 1:1, dibutuhkan luas ruangan yang besar dan bebas kolom (Gambar 2). Selain itu, penggunaan bentang lebar dan bentuk atap menjadi cara lain untuk mewujudkan suasana di bandara dengan model pesawat terbang seakan-akan sedang berada di dalam hanggar pesawat. Sistem struktur rangka dipergunakan untuk massa bangunan lantai tipikal (tower), dengan kolom di bagian luar yang diekspose dan membentuk pola diagonal, sehingga menjadi bagian estetika dari tampak bangunan yang khas, dan menambah kesan kokoh pada bangunan galeri dan kantor sewa. Selain itu juga dimaksudkan untuk memberikan fleksibilitas terhadap konsep solid dan void agar kantor sewa bebas kolom pada daerah ruang dalamnya, serta memberikan kekakuan dan kekokohan pada bangunan untuk menahan beban horisontal terutama akibat tek anan/beban udara (angin) sebagai efek dari hukum Bernoulli yang bekerja terhadap massa bangunan dan adanya beban gempa yang mungkin terjadi.

\section{Hasil Rancangan}

Berikut hasil rancangan berupa denah, tampak, dan potongan dengan menggunakan konsep hukum Bernoulli, yang menghasilkan konsep solid dan void pada denah lantai tipikal dan terlihat pada penampilan tampak bangunan (Lihat Gambar 5-8): 




Gambar 5. Denah lantai 1 (ruang pamer pesawat zaman penjajahan belanda).

Sumber: Penulis, 2019


Gambar 6. Denah lantai 2 dan 3 (ruang pamer pesawat zaman penjajahan jepang dan pesawat zaman kemerdekaan indonesia) yang memberikan kesan bangunan hanggar pesawat dan suasana di bandara.

Sumber: Penulis, 2019 


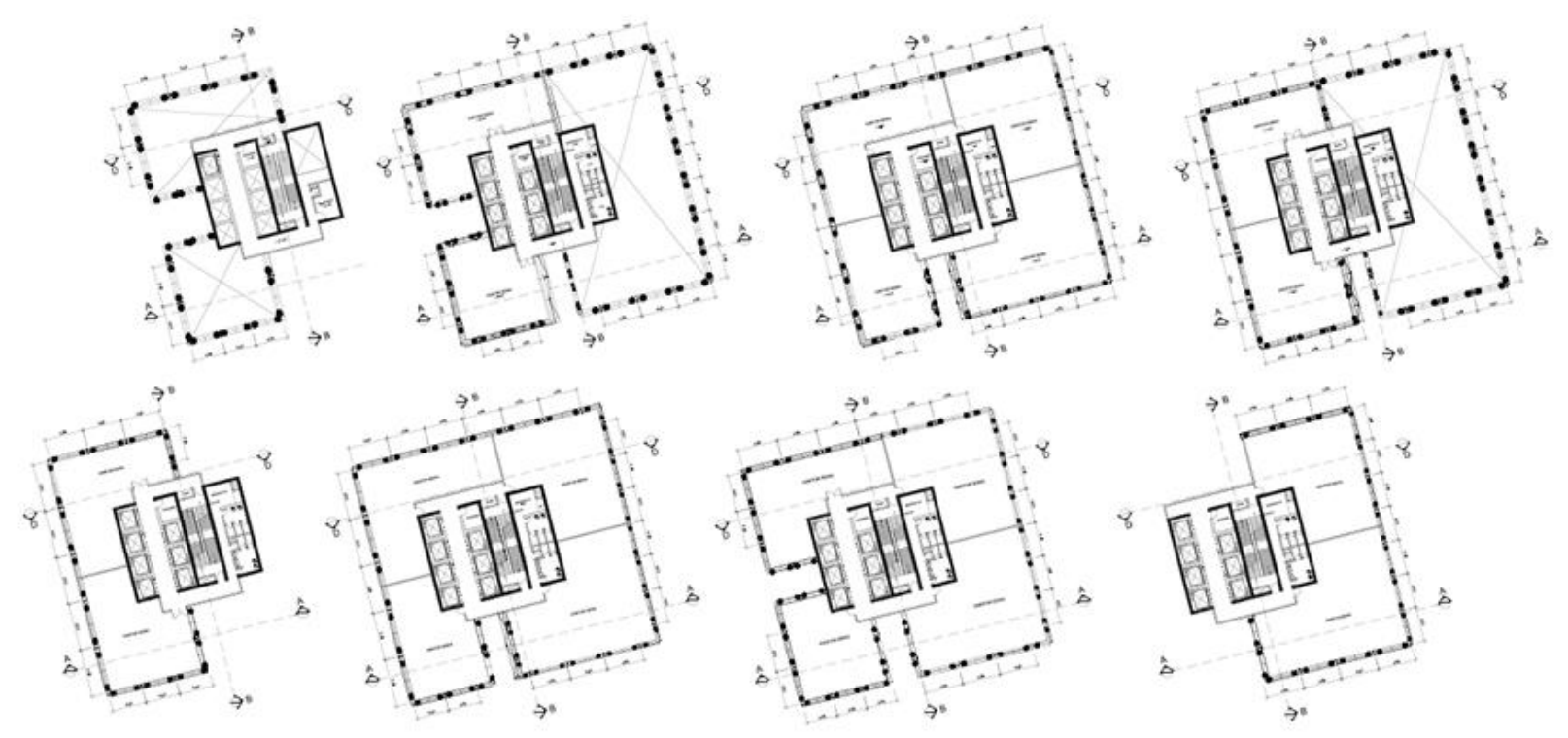

Gambar 7. Penerapan hukum bernoulli pada denah lantai tipikal (kantor sewa) yang menghasilkan konsep solid dan void.

Sumber: Penulis, 2019

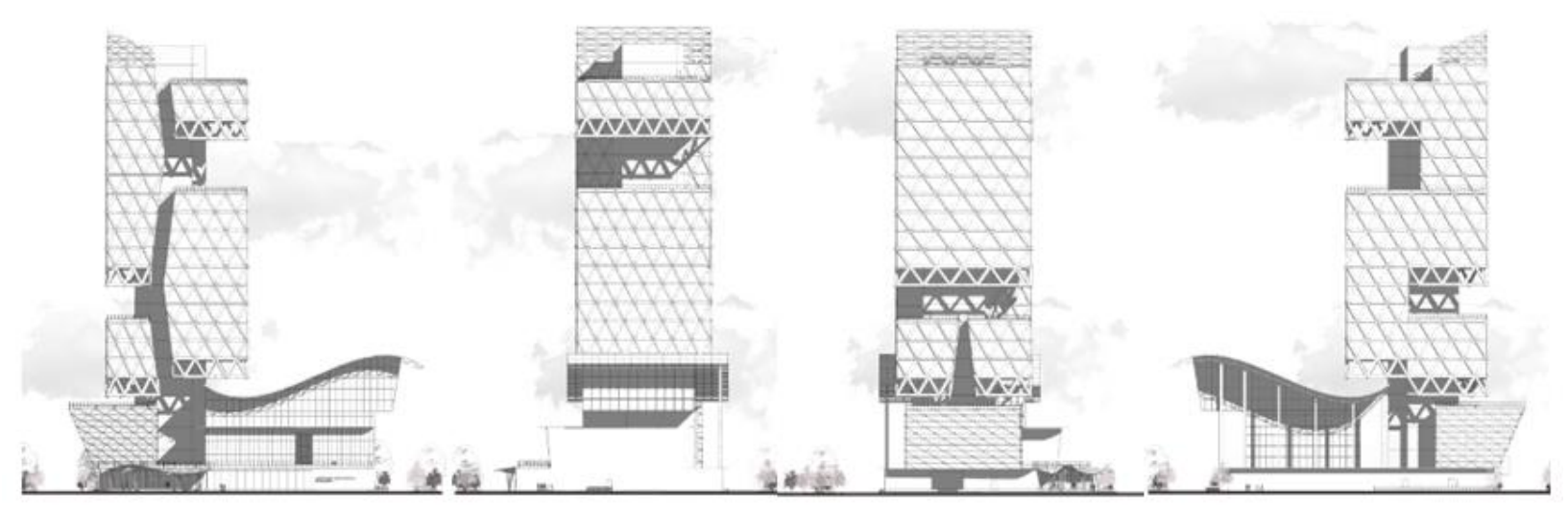

Gambar 8. Penampilan tampak bangunan.

Sumber: Penulis, 2019

\section{KESIMPULAN}

Bangunan yang memiliki tema kedirgantaraan dan mengambil konsep pergerakan aliran udara saat melewati sayap pesawat yang dikenal sebagai hukum Bernoulli sangat cocok diterapkan dalam konsep perancangan bangunan galeri pesawat terbang. Konsep aliran udara ini akan diterapkan pada tower bangunan yang memiliki fungsi kantor sewa dan membentuk solid dan void, sehingga memberikan efek aliran udara yang baik pada tampak bangunan dan berdampak terhadap temperatur di dalam bangunan, serta memberikan penampilan tampak yang menarik dan menjadi ciri khas bangunan galeri pesawat terbang. Hal ini juga didukung dengan pemilihan sistem struktur space frame pada ruang pameran pesawat skala 1:1 memerlukan luas ruangan bebas kolom dengan bentang yang lebar, dan sistem struktur rangka dengan kolom yang diekspose dan disusun secara diagonal pada tampak bangunan tower, sehingga memberikan ciri khas bangunan bandara masa kini. Dengan "disuntikan" Bangunan galeri pesawat terbang dan kantor sewa yang merupakan aplikasi konsep urban acupuncture pada kawasan "sakit" kemayoran, diharapkan dapat menjadi sumber informasi tentang sejarah Kemayoran yang mulai pudar dan sarana edukasi khususnya bagi generasi muda serta memenuhi fungsi Kemayoran yang memiliki potensi menjadi Central Business District. 


\section{REFERENSI}

Atmosudirdjo, S. P. (1982), Administrasi dan Manajemen Umum, Jakarta: Ghalia Indonesia.

Bernoulli, D. (Mei 2016), Famous Scientists. famousscientists.org. Mei 26, 2016, diakses September 28, 2018, http://www.famousscientists.org/daniel-bernoulli/, Bernoulli, D. (1738), Hydrodynamica, sive De Viribus et Motibus Fluidorum Commentarii, Basiliensis.

Casagrande, M. (2014). Paracity: Urban Acupuncture. "Public Spaces Bratislava", International Conference, Bratislava, November 20, 2014.

De Chiara, J. \& Callender, J. H. (1987), Time-Saver Standards for Building Types, New York: McGraw-Hill, Inc., https://archive.org/details/TimeSaverStandardsForBuildingTypes/page/n3.

Dictionary, C. (September 2018), https://dictionary.cambridge.org/, diakses September 28, 2018.

Dictionaries, O. (September 2018), Oxford Advanced Learner's Dictionary, A.S Hornby (1995), ed. 5, Great Britain: Oxford University Press, https://www.oxforddictionaries.com/, diakses September 28, 2018.

KBBI (September 2018), https://kbbi.web.id/, diakses September 28, 2018

Kurniawan, S. (September 2011), Kompasiana, diakses Februari 10, 2018. Jas Merah. https://www.kompasiana.com/syamsulkurniawan/550ac67a813311e178b1e2b2/jas-merah.

Lerner, J. (2016), Urban Acupuncture. Washington, D.C.: Island Press.

Neufert, E. et al, (2012), Neufert Architects'data, School of Architecture, Oxford Brookes University. UK, West Sussex: Blackwell Publishing Ltd. https://archive.org/details/Architectural_Standard_Ernst_Peter_Neufert_Architects_Data/p age/n0.

Soedirja, S. (1993), Keputusan Gubernur Kepala Daerah Khusus Ibukota Jakarta No: 475 tahun 1993, tentang Penetapan Bangunan-bangunan Bersejarah di Daerah Khusus Ibukota Jakarta sebagai Benda Cagar Budaya, https://cagarbudaya.kemdikbud.go.id/doc/file_sk/PO2015090300025-TO2016060900055774.pdf, diakses September 28, 2018 